\title{
Chapter 13 \\ The LBNL Racetrack Dipole and Sub-scale Magnet Program
}

\author{
Steve Gourlay
}

\begin{abstract}
After the test of D20, a cos-theta dipole design, the program steered away from resource-intensive magnet development to focus on simple geometries with an emphasis on fundamental technology development. This change in direction stimulated creativity and productivity. During this period 14 magnet tests were completed, a new field record of $14.7 \mathrm{~T}$ was achieved, and a new support structure, suitable for high field magnet development was implemented.
\end{abstract}

\subsection{Introduction}

The Lawrence Berkeley National Laboratory (LBNL) D20 dipole (see Chap. 6) was successfully tested in early 1997 but, having taken almost six years to complete, was considered a "near-miss" by the US Department of Energy. Taking the lessons learned from the D20 project, the program embarked on a new development path that emphasized simplicity and an incremental approach. The core of this program was based on simple racetrack coils using a double-pancake winding that simplified the lead geometry and avoided internal splices. These coil modules could be powered in a common-coil dipole or quadrupole configuration. Another aspect of the revamped program was the development of a simpler structure better suited to a research and development $(R \& D)$ environment. In the course of pursuing a new structure, it was found that small, simply constructed magnets, referred to as "subscale" magnets, using racetrack coils, could provide a rapid prototyping platform for dedicated studies. This chapter will describe the design, fabrication, and test results of some examples of the magnets produced by the program from 1998-2003.

\footnotetext{
S. Gourlay $(凹)$

Lawrence Berkeley National Laboratory (LBNL), Berkeley, CA, USA

e-mail: sagourlay@lbl.gov

(C) The Author(s) 2019 


\subsection{Overview}

During this five-year period, the program produced a series of 5 meter-scale magnets and 13 sub-scale magnets with a focus on eventually achieving fields above the range of $\mathrm{Nb}$-Ti. Each of the magnets is briefly described here and will be followed by a more detailed description of design, fabrication, and test results.

$\mathrm{RD}-2$, the first magnet of the new program, was built using $0.808 \mathrm{~mm}$ International Thermonuclear Experimental Reactor (ITER) strand manufactured by Teledyne Wah Chang Albany (TWCA). The critical current density $\left(J_{\mathrm{c}}\right)$ was $610 \mathrm{~A} / \mathrm{mm}^{2}$ at $12 \mathrm{~T}$ and $4.2 \mathrm{~K}$, notably well below the high performance strand now being used. The main purpose was to launch the new program with a quick start while the design of a larger, higher field magnet was underway.

RT-1 was a scaled-up version of RD-2. The two double-pancake coils would become the outer modules for RD-3 when combined with a new, two-layer inner coil module. A similar bolted support structure was used. The main difference was that the horizontal coil spacing was reduced from $40 \mathrm{~mm}$ to $9.5 \mathrm{~mm}$. These coils used state-of-the-art (at that time) superconductor with a $J_{\mathrm{c}}$ of $2100 \mathrm{~A} / \mathrm{mm}^{2}$, more than a factor of three greater that the ITER strand used for RD-2. The field level was the absolute limit for a bolted structure.

RD-3 was the first attempt at achieving maximum field and was the first utilization of the "key-and-bladder" concept. The first test (RD-3a) suffered a voltage breakdown during a quench between a heater trace and ground early in the test that destroyed the inner module and one of the outer modules. During the autopsy, it was discovered that a mica slip plane, inserted between the coil modules with the intent of allowing slippage, was actually strongly bonded. It was surmised that if the short had not occurred the magnet would have exhibited extensive training. Upon further investigation, it was found that the wrong type of mica paper was used. Two new coil modules were fabricated and the magnet was reassembled. RD-3b achieved $14.7 \mathrm{~T}$ at $4.2 \mathrm{~K}$ after some significant training. The next step was to build a new inner module with a bore and move toward accelerator-type field quality (RD-3c). This was the first magnet in this series that used end spacers. Because of the much-increased coil spacing, due to the bore, the field was significantly reduced (but not the complexity).

The sub-scale coil test program utilized small racetrack coils in a simple support structure. The concept was driven by several factors: the need for a less complex, versatile, high field support structure, an ability to perform tests with focused performance goals within a reasonable timeframe, and with a much smaller investment in resources. Performance data derived from these tests were then incorporated into the larger, more demanding model magnets. 
Table 13.1 RD-2 cable and design parameters

\begin{tabular}{l|l}
\hline Parameter & Value \\
\hline Coil geometry & Two-layer pancakes \\
\hline Number of turns (turns/coil) & 40 \\
\hline Coil inner-radius (mm) & 40 \\
\hline Straight section length $(\mathrm{mm})$ & 500 \\
\hline Horizontal coil spacing $(\mathrm{mm})$ & 40 \\
\hline Vertical bore spacing $(\mathrm{mm})$ & 150 \\
\hline Transfer function $(\mathrm{T} / \mathrm{kA})$ & 0.71 (linear, no iron) \\
\hline Cable & Rutherford type \\
\hline Number of strands & 30 \\
\hline Cable thickness $(\mathrm{mm})$ & 1.45 \\
\hline Cable width $(\mathrm{mm})$ & 12.34 \\
\hline Strand diameter $(\mathrm{mm})$ & 0.808 \\
\hline Manufacturer & Teledyne Wah Chang Albany \\
\hline Strand technology & ITER modified jellyroll (MJR) \\
\hline$J_{\mathrm{c}}(12 \mathrm{~T}, 4.2 \mathrm{~K})\left(\mathrm{A} / \mathrm{mm}^{2}\right)$ & 610 (TWCA) \\
\hline$B_{0}($ Max, strand) $(\mathrm{T})$ & 6.6 \\
\hline$B_{0}($ Max, cable) $(\mathrm{T})$ & 5.8 \\
\hline$B_{0}($ Max, achieved) $(\mathrm{T})$ & 5.9 \\
\hline
\end{tabular}

\subsection{RD-2 Model}

As noted above, this magnet was the first step in a program to develop a high field, accelerator quality magnet. The simple geometry, using two flat racetrack coils sandwiched together with a $10 \mathrm{~mm}$ bore, was considered compatible with the use of brittle superconductors and necessary for eventually reaching high field levels. In addition, fewer and simpler parts were used in fabricating these coils compared to the more conventional cos-theta cross-section coils.

The designation RD-2 is an anachronism from an earlier naming convention where the number of coil modules, in this case " 2 ," would be followed by a sequence number. Hence, the original name of this magnet was RD-2-01. The nomenclature was abandoned for subsequent models as it was deemed to be too complicated.

The ongoing program for the development and utilization of brittle superconductors for accelerator magnets at LBNL has been focused on coils with a simple racetrack geometry. The ultimate goal of the program was to develop acceleratorquality dipoles with fields up to $15 \mathrm{~T}$. This goal was approached by building a few lower field magnets to demonstrate the feasibility of the design, develop fabrication techniques, and understand relevant performance parameters.

Details of RD-2 have been described previously (Gourlay 1998; Chow et al. 1998a, b; Jackson et al. 2001). An overall summary of the magnet design, fabrication, and test is given here. The main parameters are summarized in Table 13.1. 
Fig. 13.1 RD-2 coil module

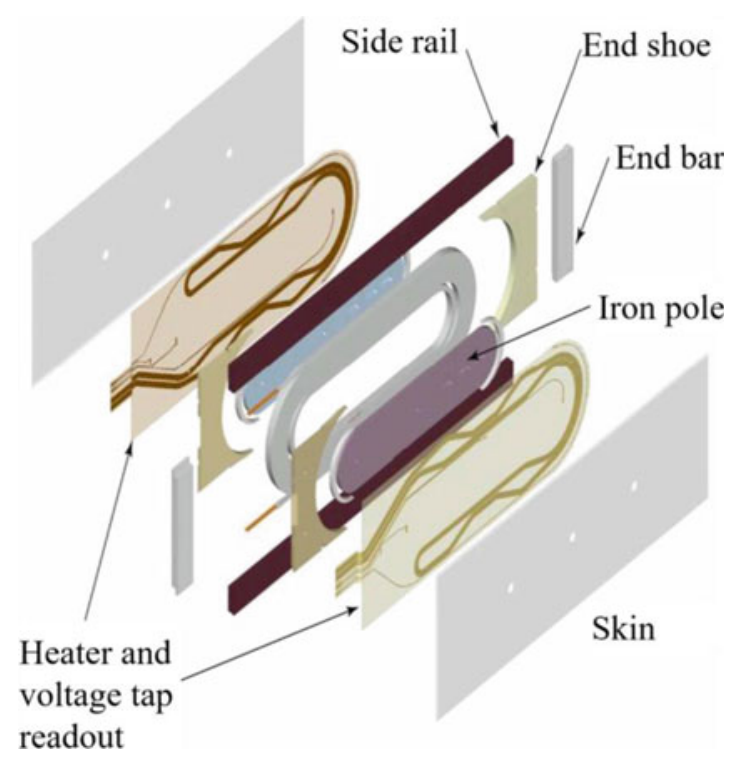

The cable is made from $0.808 \mathrm{~mm}$ diameter strand manufactured by TWCA for the ITER project, which had a $J_{\mathrm{c}}$ of about $610 \mathrm{~A} / \mathrm{mm}^{2}$ at $12 \mathrm{~T}$ and $4.2 \mathrm{~K}$. Short sample measurements of single strands indicate a bore field of $6.64 \mathrm{~T}$ at short sample. A single measurement of a bifilar cable sample gave a lower value of $5.87 \mathrm{~T}$.

\subsubsection{Coil Module}

The fundamental component of this design is the coil module, which consists of a double-layer coil contained in a support structure. The coil module components are shown in Fig. 13.1.

\subsubsection{Support Structure}

The magnet structural support was designed for modular coil assembly (Fig. 13.2). End forces and vertical forces (forces in the plane of the racetrack coils) are supported from within the coil module. A vertical pre-stress of $50 \mathrm{MPa}$ is applied through $50 \mathrm{~mm}$ thick aluminum-bronze $(\mathrm{AlCu})$ rails running the full magnet length in the coil package, and an end preload of $50 \mathrm{MPa}$ was applied using a series of setscrews loaded against the end shoes. To apply horizontal pre-stress and structural support, the coil packages arc sandwiched between stainless-steel clamping bars pulled together by aluminum tension bolts. The horizontal preload is $16 \mathrm{MPa}$ at 
Fig. 13.2 RD-2 structure components

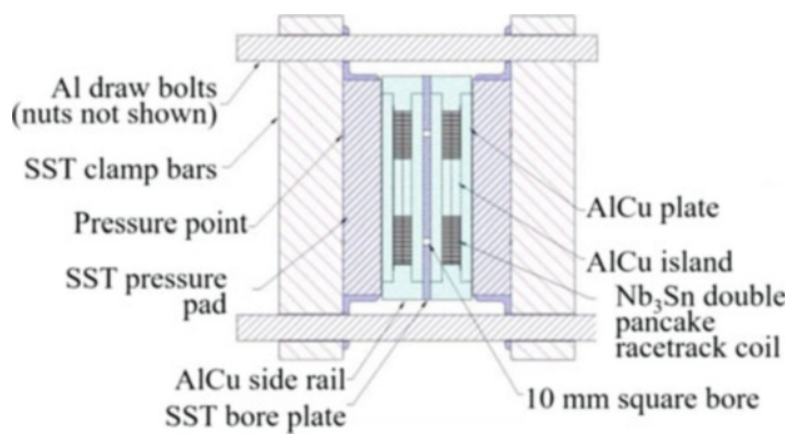

Table 13.2 RD-2 preload combinations

\begin{tabular}{l|l|l|l|l}
\hline \multirow{2}{*}{ Magnet } & Coil preload (MPa) & 4.2 K Horizontal & 4.2 K Vertical \\
\cline { 2 - 5 } & 300 K Horizontal & 300 K Vertical & 30 & 30 \\
\hline RD-2-a & 14 & 50 & 6 & 30 \\
\hline RD-2-b & 6 & 50 & 6 & 7 \\
\hline RD-2-c & 6 & 21 & & \\
\hline
\end{tabular}

room temperature and increases to $30 \mathrm{MPa}$ at liquid helium temperatures. This simple support structure allows easy change-out of coil modules and independent control of vertical and horizontal pre-stress. Several tests of this magnet were done under varying preload conditions.

\subsubsection{Fabrication}

The double-layer coils were wound around a center island (pole piece) on a flat plate with a ramp between layers to avoid internal splices. All metal parts, which would be in contact with the coil, were made from $\mathrm{AlCu}$ in order to survive the hightemperature heat treatment and because of its relatively high heat transfer coefficient compared to other materials such as stainless steel. During the winding process, strips of stainless-steel foil were wrapped around the cable in strategic locations to provide voltage taps. All metal parts were insulated with $0.086 \mathrm{~mm}$ thick strips of mica paper to augment the electrical integrity of the coil and provide a parting plane if needed.

\subsubsection{RD-2 Test Results}

Taking advantage of the flexibility of the RD-2 design, we performed a series of tests with reduced horizontal and vertical preload. Three preload combinations, as summarized in Table 13.2, were tested. 


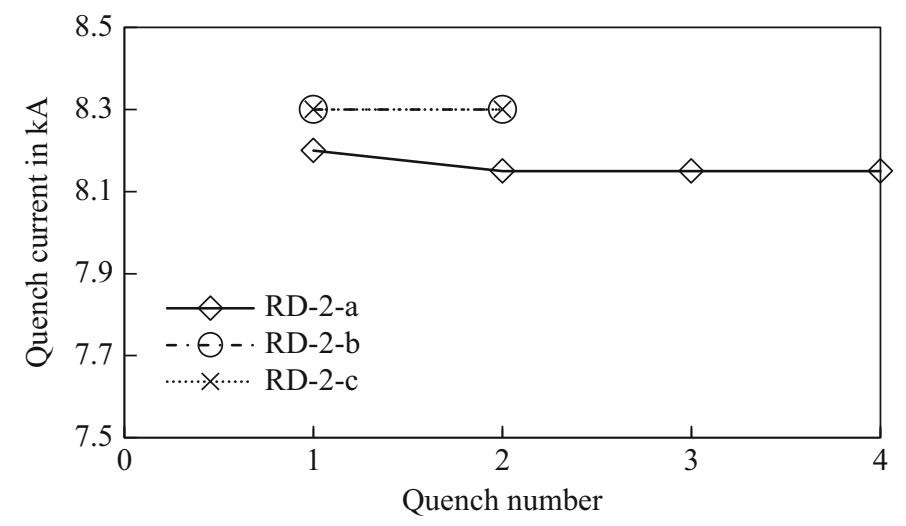

Fig. 13.3 RD-2 training history

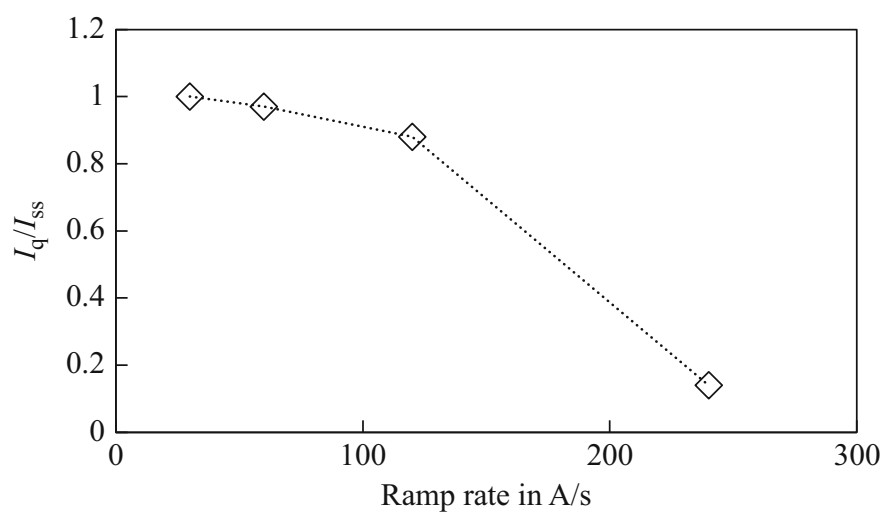

Fig. 13.4 RD-2 ramp rate dependence

The preliminary design was for a $10 \mathrm{~mm}$ aperture magnet (40 $\mathrm{mm}$ coil spacing) with an emphasis on maintaining the simplicity of the racetrack geometry.

RD-2-a (originally named RD-2-01) required no training and achieved a thermally dependent $4.4 \mathrm{~K}$ plateau current of $8.29 \mathrm{kA}$ on the first ramp, slightly above the limit based on the cable measurement. The mechanically modified versions of the magnet (RD-2-b and RD-2-c, originally named RD-2-02 and RD-2-03) performed identically to the original load configuration, despite the sizable differences in loading and loading histories. During the initial cool-down, 18 high current quenches were used to establish training, ramp rate, and temperature dependencies. Figure 13.3 shows the spontaneous quench history of the RD-2 series, and in Fig. 13.4 the ramp rate dependence is shown. More details can be found in Gourlay et al. (1999a, b). 


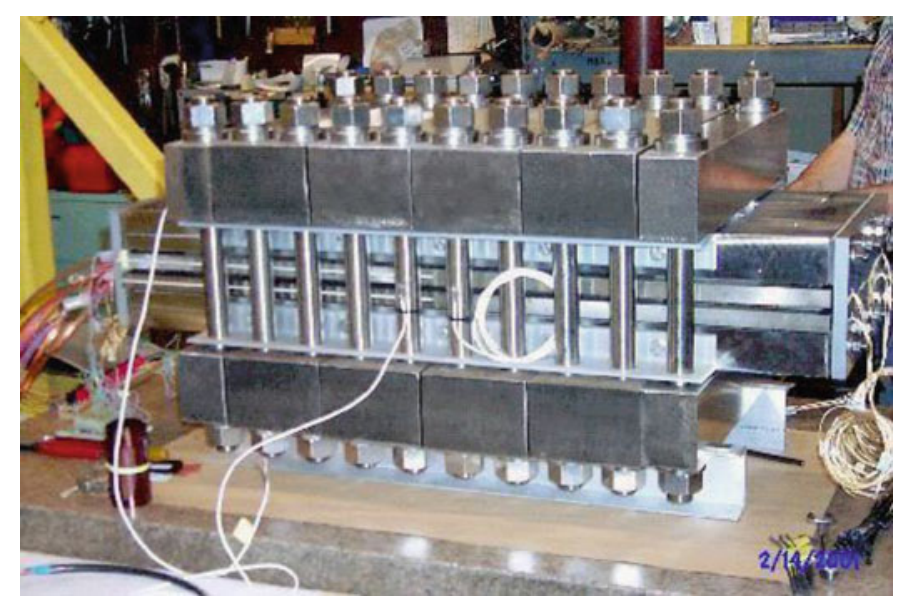

Fig. 13.5 RT-1 support structure

Table 13.3 RT-1 design parameters

\begin{tabular}{l|c}
\hline Parameter & Value \\
\hline Coil spacing $(\mathrm{mm})$ & 9.5 \\
\hline Computed quench field at 4.2 K (T) & 12.2 \\
\hline Peak field (T) & 12.36 \\
\hline Quench current $(\mathrm{kA})$ & 10.5 \\
\hline Straight section length (mm) & 500 \\
\hline Number of turns (half magnet) & 49 \\
\hline Nominal height of each main coil (mm) & 80 \\
\hline Minimum coil bend radius $(\mathrm{mm})$ & 70 \\
\hline Vertical bore spacing $(\mathrm{mm})$ & 220 \\
\hline
\end{tabular}

\subsection{RT-1 Model}

With the success of RD-2 demonstrating proof-of-principle, the team at LBNL continued work on a high field, $\mathrm{Nb}_{3} \mathrm{Sn}$ racetrack dipole. These next steps systematically led to the construction of a $14 \mathrm{~T}$ common-coil dipole.

During the design phase of the $14 \mathrm{~T}$ dipole the program took advantage of an opportunity to test the outer coil modules prior to final assembly in RD-3. The incorporation of several new fabrication techniques and the much higher field/ stresses that would be encountered in RD-3 encouraged us to take this interim step as a means of substantiating fundamental design assumptions. The highest field, and therefore the highest stresses, were obtained by simply sandwiching the two outer coil modules between a scaled-up version of the bolted support structure successfully used for RD-2 (Fig. 13.5). The RT-1 design parameters are given in Table 13.3. 
Fig. 13.6 RT-1 coil module support structure. The coil modules are a larger version of the design used by RD-2 shown in Fig. 13.2

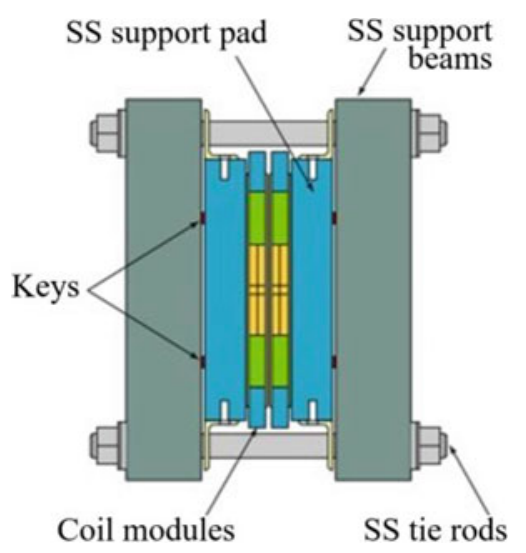

\subsubsection{Support Structure}

Vertical preload and support of the magnet coil windings is completely provided by the coil module structure (Fig. 13.6). To maximize the bore field and provide a more efficient cross-section, the amount of material in the support structure between the bore and the inner conductor and adjacent coil layers must be minimized. This minimization required the use of thin sheets of stainless-steel "skins," replacing the thick AlCu plates used for RD-2 (see Fig. 13.2). The previous method of using fasteners screwed into the $\mathrm{AlCu}$ plates was replaced by welding these skins to the module while being loaded hydraulically in the vertical and axial directions. The magnitude of the vertical pre-stress (approximately $43 \mathrm{MPa}$ at $4.2 \mathrm{~K}$ ) was determined by the requirement that the conductor remain in contact with the support structure interface at all times. The ratios of the vertical and axial preloads were calculated such that the stresses in the end and transition region were as uniform as possible under maximum Lorentz loading.

\subsubsection{Assembly}

The coil was loaded in steps, alternating between axial and vertical to minimize the development of shear between the coil/skin interfaces. The load was monitored with resistive strain gauges attached to the skins, directly from the press and axial loader cylinder pressures, and by measuring the coil displacement. During cycling the coils were subjected to loads exceeding $100 \mathrm{MPa}$. Final preload values (after welding) were around $40 \mathrm{MPa}$ in the vertical direction and approximately $20 \mathrm{MPa}$ axially. These values increased by $20-30 \%$ on cool-down.

To minimize coil bending, the coil modules were placed between two $60 \mathrm{~mm}$ thick stainless-steel pads that were supported by structural beams through a set of "pressure point" keys. The pads and keys ensure minimum bending within the coils 
regardless of the structural beam deformation. The beams, $114.3 \mathrm{~mm}$ thick, were restrained with tie rods across the coils. The beams are longitudinally split into four parts along the straight section of the coils, with two special beams at the ends (compare with Fig. 13.5). Straight section beams were tied with two tie rods on each side, and end beams contained single tie rods (compare with Fig. 13.5). The tie rods are $38.1 \mathrm{~mm}$ diameter stainless steel. The bolted support system, while acceptable for the 6 T RD-2 magnet, was marginally adequate for the $12 \mathrm{~T}$ coil test. Although in this case the structure served the purpose, it is not considered a viable choice for high field magnets. In order to prevent displacement due to the Lorentz forces, the total force exerted by the structure (pre-stress) would have to exceed the total Lorentz load at maximum current. At full field the maximum stress in the beams and tie rods (cold) is $280 \mathrm{MPa}$ and $300 \mathrm{MPa}$, respectively. The maximum torque that could be applied to the bolts was $1.02 \mathrm{kN}$.m, which resulted in a bolt stress of approximately $90 \mathrm{MPa}$, about a quarter of what is required. To prevent separation during excitation, the required bolt stress would need to be about $360 \mathrm{MPa}$ (warm), exceeding the yield by almost a factor of two. With no pre-stress the coils would separate by approximately $1.9 \mathrm{~mm}$. Based on the applied room temperature pre-stress of the bolts, the measured coil separation was reduced to $1.6 \mathrm{~mm}$.

\subsubsection{Test Results}

The training history of RT-1 is shown in Fig. 13.7. Two of the first three quenches were associated with runaway ramping of the coils due to noise feeding into the control system. Even though the magnet was in the midst of ramping down at $6.8 \mathrm{~A} / \mathrm{s}$ during the second quench, voltage tap signals indicated evidence of a motioninduced event. Given that this quench occurred at $79 \%$ of short sample, it may be assumed to have had an effect on the subsequent quench behavior. On the fourth quench, the coils reached the limit predicted by the manufacturer's virgin strand

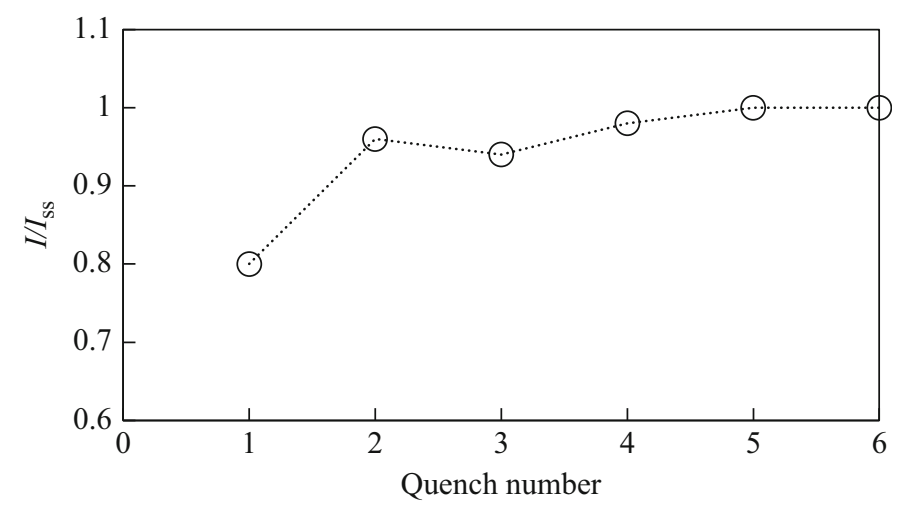

Fig. 13.7 RT-1 training history 
Table 13.4 RT-1 strand parameters

\begin{tabular}{l|l}
\hline Parameter & Value \\
\hline $\mathrm{Cu}(\%)$ & 59.5 \\
\hline $\mathrm{Cu}$ RRR & 15 \\
\hline$I_{\mathrm{c}}(12 \mathrm{~T}, 4.2 \mathrm{~K})(\mathrm{A})$ & 446 \\
\hline$J_{\mathrm{c}}(12 \mathrm{~T}, 4.2 \mathrm{~K})\left(\mathrm{A} / \mathrm{mm}^{2}\right)$ & 2190 \\
\hline$I_{\mathrm{c}}(15 \mathrm{~T}, 4.2 \mathrm{~K})(\mathrm{A})$ & 230 \\
\hline$J_{\mathrm{c}}(15 \mathrm{~T}, 4.2 \mathrm{~K})\left(\mathrm{A} / \mathrm{mm}^{2}\right)$ & 1129 \\
\hline Length $(\mathrm{m})$ & 5000 \\
\hline Number of pieces & 14 \\
\hline Manufacturer & $\begin{array}{l}\text { Oxford Superconducting } \\
\text { Technology }\end{array}$ \\
\hline Strand technology & MJR \\
\hline
\end{tabular}

Table 13.5 RT-1 cable parameters

\begin{tabular}{l|l}
\hline Parameter & Value \\
\hline Strand diameter $(\mathrm{mm})$ & 0.8 \\
\hline Number of strands & 26 \\
\hline Thickness $(\mathrm{mm})$ & 1.408 \\
\hline Width $(\mathrm{mm})$ & 11.338 \\
\hline Length/coil $(\mathrm{m})$ & 387 \\
\hline
\end{tabular}

measurement. These values have historically been systematically conservative. Short sample cable measurements predicted a 3.5\% higher quench current. Following two more quenches, a plateau corresponding to the cable predicted limit was reached at $10.5 \mathrm{kA}$, indicating that there was no degradation during cabling or fabrication of the coils. The bore field at this current was $12.2 \mathrm{~T}(12.36 \mathrm{~T}$ peak field on the winding), more than twice that of RD-2. This field level was made possible by the availability of state-of-the-art (at that time) superconductor with a non- $\mathrm{Cu} J_{\mathrm{c}}$, of over $2000 \mathrm{~A} / \mathrm{mm}^{2}$ at $12 \mathrm{~T}$ and $4.2 \mathrm{~K}$, a factor of three increase compared to the conductor used for RD-2.

The RT-1 strand and cable parameters are listed in Tables 13.4 and 13.5, respectively. While the conductor non-copper $J_{\mathrm{c}}$ exceeded $2000 \mathrm{~A} / \mathrm{mm}^{2}$, the residual resistivity ratio (RRR) for this wire was approximately 15 . This low RRR was caused by nearly total conversion of the $\mathrm{Nb}$ barrier and $\mathrm{Sn}$ leakage into the copper matrix. At that time, a solution was proposed to increase the RRR closer to a value of 70 by reducing the heat treatment time. One of the possible disadvantages that one might anticipate with such a low RRR is the development of instabilities in the conductor. The coils showed very little training however, and in fact the quench protection was simplified due to the increased quench velocity (about a factor of three over a conductor with an RRR of 50) and subsequently reduced the hotspot temperature in the coil. 


\subsubsection{Conclusion}

The outer coils for RD-3 were tested in a high field/stress configuration and achieved short sample with little training. The new skinning method proved to be an effective way of providing preload, producing very robust coil packages that were able to withstand large displacements without quenching. Within the measurement errors, there was no indication of stress degradation due to either high loading at room temperature $(>100 \mathrm{MPa})$ or during excitation $(\sim 50 \mathrm{MPa})$. With the addition of the inner coil module in the RD-3 configuration, the field in the outer coils would decrease to approximately $10.4 \mathrm{~T}$, but the stress under Lorentz loading will double to approximately $100 \mathrm{MPa}$. More details on the design, fabrication, and test of RT-1 may be found in Gourlay et al. (2000) and Benjegerdes et al. (2001).

\subsection{RD-3 series}

The next step toward higher fields was to combine the two coil modules tested in RT-1 with an inner coil module in an attempt to reach fields in the range of $14 \mathrm{~T}$. These coil modules are assembled in RD-3, a common-coil configuration. At the time of the RT-1 test the group still planned to use the wire wrap method to apply the necessary preload. The original design concept is shown in Fig. 13.8.

Fig. 13.8 Original concept for RD-3 using wire wrap

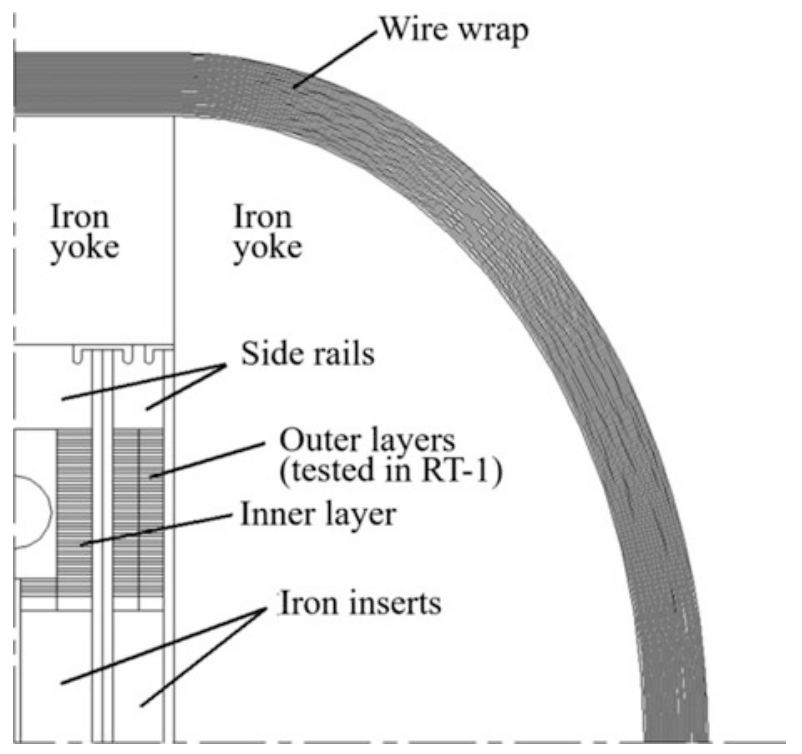


Fig. 13.9 RD-3 crosssection with key-andbladder support structure

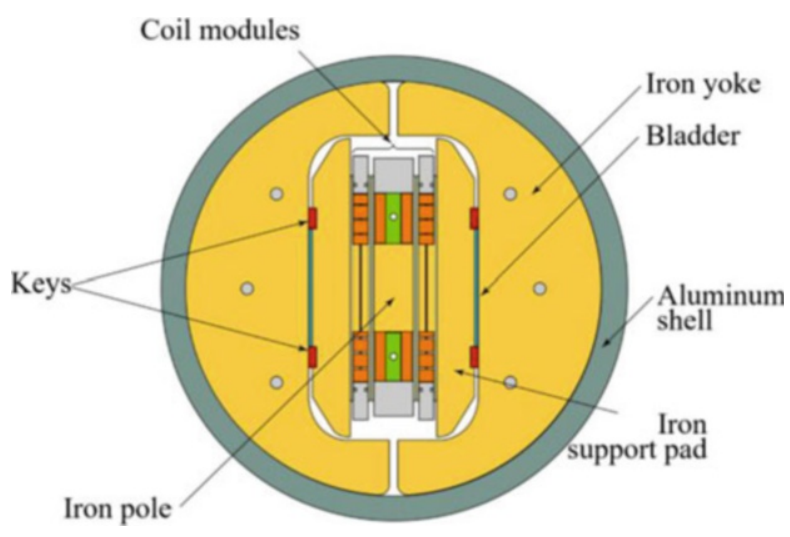

Though the wire wrap method was successfully demonstrated on D20, it was felt by many in the group that the process was much too complicated and timeconsuming. So, what were the alternatives? The bolted structure used for RD-2 and RT-1 could not supply the required preload. Coil separation in this case could not be tolerated. In 1997, S. Caspi was exploring the use of epoxy-filled bladders to provide preload, based on a concept successfully used on the Versatile Electron Cyclotron Resonance (ECR) Ion Source for Nuclear Science (VENUS ECR) by Clyde Taylor, former head of the LBNL group. A. Lietzke provided more input on the concept. After more study, S. Caspi presented the idea to S. Gourlay, who suggested using keys to lock in the preload and the use of an aluminum shell instead of stainless steel, which would increase the preload on cool-down as had been successfully demonstrated by the group at the University of Twente for the MSUT magnet (den Ouden et al. 1997). The concept seemed solid but proving it was more complicated. S. Caspi immersed himself in fully developing the idea and quickly realized that a one-third scale model structure would exhibit the same strain levels as full-scale. With the permission of A. Jackson, who was the program head at the time, the team was given two weeks to demonstrate the new concept by building and cold testing an instrumented sub-scale structure model. The new technique (Caspi et al. 2001, Hafalia et al. 2002) was successfully demonstrated and the design for the RD-3 support structure was changed to the so-called key-and-bladder structure shown in Fig. 13.9. Some of the assembly steps are shown in Fig. 13.10(a-c).

\subsubsection{Development of the Key-and-Bladder Concept}

The large Lorentz forces mean that a cantilever structure is too soft. That effect was demonstrated in RT-1, when the structure allowed the coil halves to separate by more than $1.5 \mathrm{~mm}$ at $12 \mathrm{~T}$. The use of a circular shell is more efficient in providing pre-stress that can effectively prevent the coils from separating. The force balance between shell and coils takes place in several steps. Initially the shell pre-stress is set 


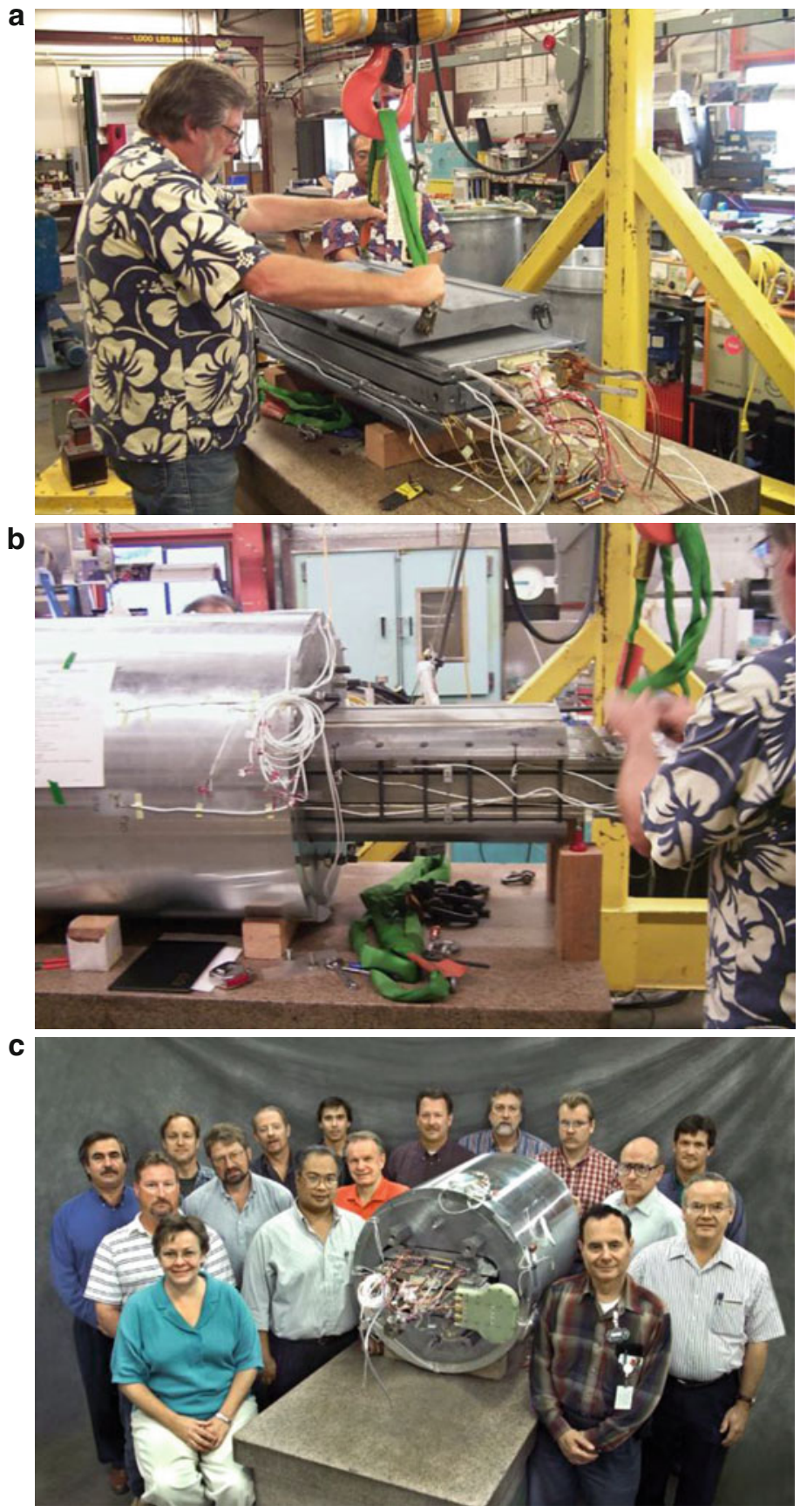

Fig. 13.10 (a) RD-3 coil pack assembly; (b) inserting the coil pack into support structure; and (c) fully assembled magnet including the LBNL team 
Table 13.6 RD-3 magnet parameters

\begin{tabular}{l|l}
\hline Parameter & Value \\
\hline Main coil spacing $(\mathrm{mm})$ & 25 \\
\hline Computed quench field at $4.2 \mathrm{~K}(\mathrm{~T})$ & 14.6 \\
\hline Peak field, inner layer $(\mathrm{T})$ & 14.9 \\
\hline Peak field, outer layer $(\mathrm{T})$ & 11.5 \\
\hline Maximum current (predicted) (kA) & 10.9 \\
\hline Number of main coil layers & 3 \\
\hline Straight section length (mm) & 500 \\
\hline Number of turns (half magnet) & $50+49+49$ \\
\hline Nominal height of each main coil $(\mathrm{mm})$ & 80 \\
\hline Minimum bend radius $(\mathrm{mm})$ & 70 \\
\hline Vertical bore spacing $(\mathrm{mm})$ & 220 \\
\hline Yoke outer height and width $(\mathrm{mm})$ & 300 \\
\hline Cu $(\%)$ inner/outer $(\%)$ & $47.3 / 57.3$ \\
\hline$I_{\mathrm{c}}$ inner $12 \mathrm{~T} / 15 \mathrm{~T}(\mathrm{~A})$ & $540 / 265$ \\
\hline$I_{\mathrm{c}}$ outer $12 \mathrm{~T} / 15 \mathrm{~T}(\mathrm{~A})$ & $382 / 180$ \\
\hline
\end{tabular}

Table 13.7 RD-3 strand parameters

\begin{tabular}{l|l|l}
\hline Strand & Inner & Outer \\
\hline $\mathrm{Cu}(\%)$ & 51.3 & 59.5 \\
\hline$I_{\mathrm{c}}(12 \mathrm{~T}, 4.2 \mathrm{~K})(\mathrm{A})$ & 485 & 446 \\
\hline$J_{\mathrm{c}}(12 \mathrm{~T}, 4.2 \mathrm{~K})\left(\mathrm{A} / \mathrm{mm}^{2}\right)$ & 1981 & 2190 \\
\hline$I_{\mathrm{c}}(15 \mathrm{~T}, 4.2 \mathrm{~K})(\mathrm{A})$ & 250 & 230 \\
\hline$J_{\mathrm{c}}(15 \mathrm{~T}, 4.2 \mathrm{~K})\left(\mathrm{A} / \mathrm{mm}^{2}\right)$ & 1021 & 1129 \\
\hline Length $(\mathrm{m})(\mathrm{pieces})$ & $9035(16)$ & $5000(14)$ \\
\hline Diameter $(\mathrm{mm})$ & 0.8 & 0.8 \\
\hline Manufacturer & Oxford Superconducting Technology \\
\hline Strand technology & MJR
\end{tabular}

to around $150 \mathrm{MPa}$ by the bladders and keys. During cool-down the stress increases to around $250 \mathrm{MPa}$ due to the relatively large shrinkage of the aluminum shell and remains unchanged during operation. The force on the shell is reacted by the force between the symmetrical halves of the magnet. Most of the reactive force will be carried by the iron pole. The Lorentz force loads the coils and unloads the bore, posts, and side rails. The coil modules will separate only after the Lorentz force overcomes the reactive force, which is not expected to happen below $16 \mathrm{~T}$-well above the short sample field for RD-3.

The integrated double-bore Lorentz force at $16 \mathrm{~T}$ is $F_{x}=22 \mathrm{MN} / \mathrm{m}, F_{y}=-3.0$ $\mathrm{MN} / \mathrm{m}$, and $F_{z}=700 \mathrm{kN}$. The ANSYS finite element software (ANSYS Inc., Canonsburg, PA) was used to calculate the magnetic forces and perform the structural analysis. The load case progression followed the steps of assembly, cool-down. The shell pre-stress of RD-3 was designed for an equivalent field of $16 \mathrm{~T}$, providing a sufficient safety margin for the current design field and was later confirmed by strain gauge measurements. Parameters for RD-3 are shown in Tables 13.6, 13.7, and 13.8. 
Table 13.8 RD-3 cable parameters

\begin{tabular}{l|l|l}
\hline Cable & Inner & Outer \\
\hline Strand number & 40 & 26 \\
\hline Thickness $(\mathrm{mm})$ & 1.418 & 1.408 \\
\hline Width $(\mathrm{mm})$ & 17.159 & 11.338 \\
\hline Length $(\mathrm{m} / \mathrm{coil})$ & 210 & 387 \\
\hline
\end{tabular}

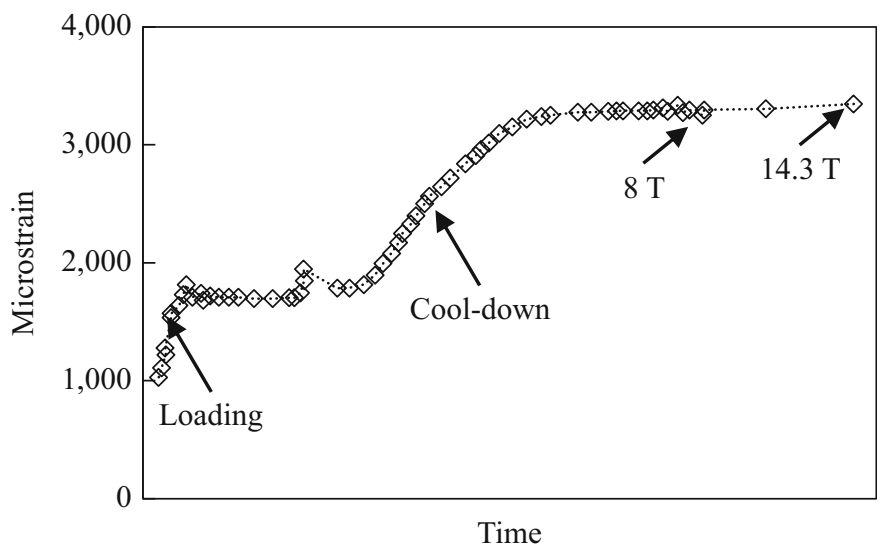

Fig. 13.11 RD-3b pre-stress history, from loading through cool-down and magnet excitation for the first cycle

RD-3 was a $\mathrm{Nb}_{3} \mathrm{Sn}$ common-coil dipole designed to exceed $14 \mathrm{~T}$. At that field, the average Lorentz side force is $15.4 \mathrm{MN} / \mathrm{m}$, or a total of $12.0 \mathrm{MN}$ over the $780 \mathrm{~mm}$ coil length, acting to push the windings apart. As a means to manage these large forces, a new support structure design was developed for RD-3 that uses inflatable bladders as a temporary internal "press" to load the coil modules inside an aluminum shell. This configuration utilized the best features of the simple cantilevered structure used in the successful test of RT-1, but was intended to eliminate coil displacement.

The bladders, placed between the coil pack and the iron yoke, simultaneously compressed the coil pack to $70 \mathrm{MPa}$, and tensioned a $40 \mathrm{~mm}$ thick structural aluminum shell to $155 \mathrm{MPa}$. The shell was highly instrumented with strain gauges to record all phases of assembly and testing. Keys were inserted to maintain pre-stress when the bladders were deflated and removed, leaving the shell with $140 \mathrm{MPa}$ of tension. Measurements were compared with finite element analysis using ANSYS to determine the final stress in the shell and coil.

No creep was observed over many days at room temperature. During cool-down, stress in the shell increased to the desired preload of $250 \mathrm{MPa}$ (Fig. 13.11).

This system simplifies magnet assembly substantially, and easily contains the large Lorentz forces without the need for precision parts. The magnet structure reaches maximum stress after cool-down. During operation, reactive forces between the two halves of the magnet are replaced with Lorentz forces within the coils, 


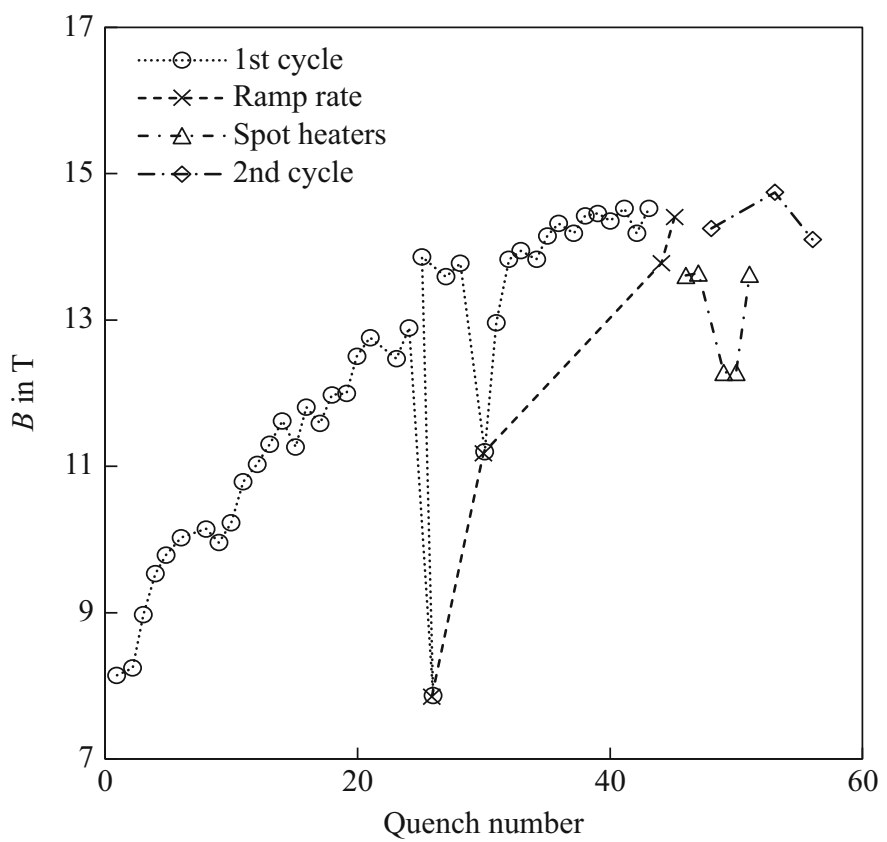

Fig. 13.12 RD-3b quench history

leaving the stress in the structure unchanged. As long as the coil structure is pre-stressed beyond the Lorentz forces, the two coil halves will not separate.

\subsubsection{RD-3a, RD-3b}

The final assembly of RD-3a was completed in August 2000. During the first ramp, an insulation failure occurred, which resulted in arc damage to two coils. The damaged coils were rebuilt and RD-3b was tested in two test campaigns: one starting in late April 2001, followed by a thermal cycle in early June 2001. All the $\mathrm{Nb}_{3} \mathrm{Sn} /$ $\mathrm{Nb}$-Ti joint resistances were measured, and found to be very low $(R<1 \mathrm{n} \Omega)$. The first training quench occurred at $8.1 \mathrm{~T}$ (Fig. 13.12). The magnet trained slowly, exceeding a field of $14 \mathrm{~T}$ after 35 quenches. A plateau was reached at an average value of approximately $14.2 \mathrm{~T}$. The quenches at this field level still however, exhibited features typical of motion-induced training quenches, indicating that the magnet may not have been at the short sample limit.

Most of the training quenches below 13.7 T originated in the central (high field) section of the inner coil module. Above this field, most of the quenches originated in the outer coil modules. 
After a thermal cycle, the first training quench (Q48) occurred at the previously established plateau of $14.2 \mathrm{~T}$, indicating excellent retention of its previous training. During this test, the magnet reached a bore field of $14.7 \mathrm{~T}$, which is near the short sample critical current limit for both coils. More details on RD-3b can be found in Benjegerdes et al. (2001).

$\mathrm{RD}-3 \mathrm{~b}$ showed that $\mathrm{Nb}_{3} \mathrm{Sn}$ coils wound in the common-coil (or racetrack dipole) configuration can achieve unprecedented dipole fields (14.7 T) in accelerator magnets. The magnet performed within the range predicted by short sample strand data, and behaved mechanically as predicted by TOSCA (now part of the Opera Simulation Software, Dassault Systèmes) and ANSYS models. There was no degradation in critical current due to cabling or due to the Lorentz loads during operation.

\subsubsection{RD-3c: Continuation of the RD Series-Field Quality}

\subsubsection{Magnet Design Features}

After developing a coil geometry and support structure that adequately supports the coil, the next step was to explore cross-section designs that provided acceleratorgrade field quality. Racetrack cross-sections that have good magnetic field quality are intrinsically more complex, and the simple cross-sections will need to be augmented. Efficient magnetic field generation also requires that the conductor be as close as possible to the bore. A series of designs was planned that progressively implemented field-quality features, starting with the simplest. The first (and as it turned out, the last) in this series, RD-3c, was successfully tested in the spring of 2002.

$\mathrm{RD}-3 \mathrm{c}$ was envisioned as an economical test of the ability to design, build, and measure a reliable, accelerator-quality, common-coil magnet. Accordingly, the following constraints were imposed.

1. Reuse RD-3b's outer coils, yoke, and shell structure.

2. Reduce the associated large field errors to accelerator levels with the simplest harmonic-correction coils.

3. Make no effort to correct either the end, or up-down asymmetric harmonics (best corrected by changes in the iron).

4. Design and fabricate the correction coils from single-layer, flat racetrack coils with only one spacer per layer.

5. Package the correction coils as a double-layer insert coil-module, with no internal splices.

6. Provide a mid-plane "bore-plate" that would allow the insertion of a $25 \mathrm{~mm}$ outer diameter (OD) warm, rotating-coil probe.

7. Fabricate and assemble the insert module in a manner that might improve the training rate (compared to that of $\mathrm{RD}-3 \mathrm{~b}$ ).

8. Apply diagnostics that could better localize conductor motions. 
Fig. 13.13 RD-3c crosssection and coil configuration

Fig. 13.14 RD-3c inner coil module showing the "s-bend" transition between coils across the bore
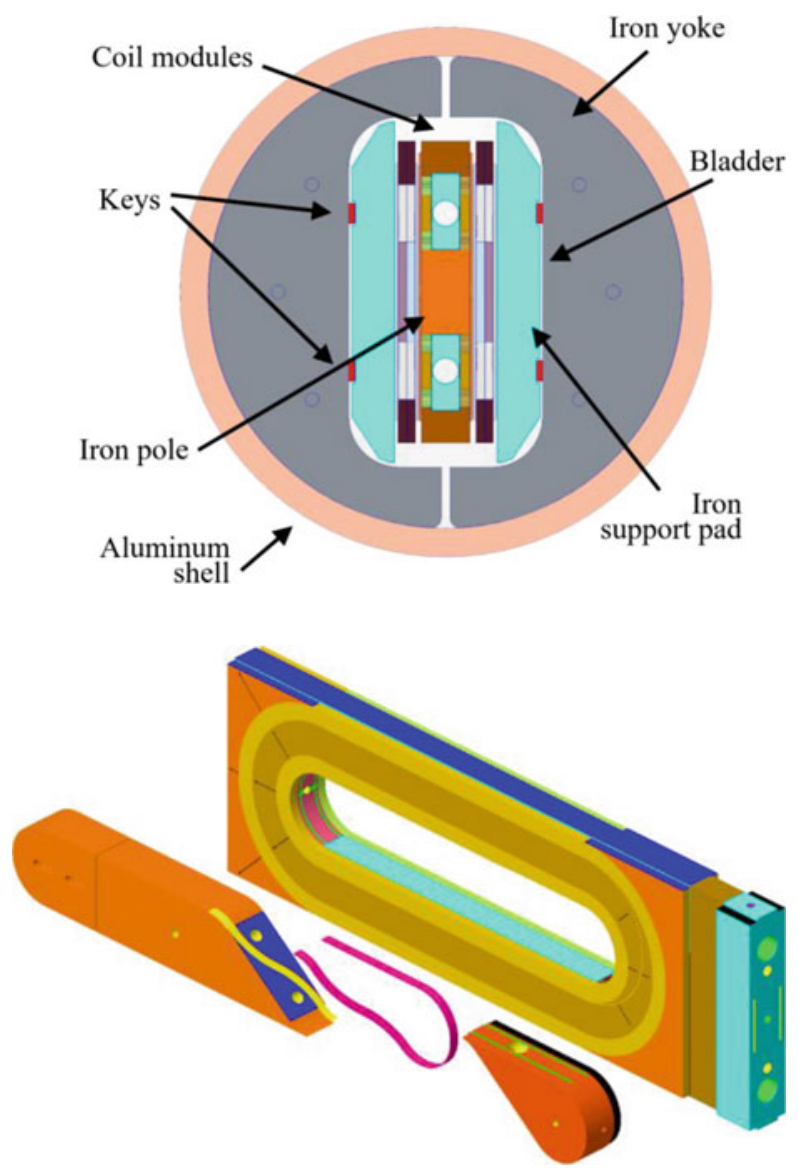

Figure 13.13 shows the magnet cross-section that resulted from the above constraints. The harmonic-correction insert module was clamped between RD-3b's outer coil modules.

As in RD-3b, an AlCu bore-plate separated two single-layer insert coils. An internal S-bend ramp supplied the required current reversal across the bore-plate (avoiding an internal splice) (Fig. 13.14).

Each coil used a wide coil-spacer near each bore-hole to counteract the large positive sextupole from the outer coils and each coil layer had 16 turns in two equal blocks. The bore-plate was thick enough $(39.5 \mathrm{~mm})$ to avoid excessive deformation of the bore-hole, and allow access for a $35 \mathrm{~mm}$ OD anti-cryostat. The insert module was reacted and encapsulated as in previous coil modules. It was not, however, "exercised" in a press before welding. Final pre-stress, applied by bladders between iron pads and the yoke, was maintained via iron keys (as before for RD-3b). Due to the aluminum-iron containment system, the average $300 \mathrm{~K}$ coil face pre-stress $(\sim 65$ $\mathrm{MPa}$, scaled from the measured Al-shell stress) nearly doubled during cool-down to the $4.4 \mathrm{~K}$ operating temperature. RD-3c's performance parameters are compared 
Table 13.9 RD-3c performance parameters

\begin{tabular}{l|l|l}
\hline Magnet & RD-3c $\mathrm{c}^{\mathrm{a}}$ & RD-3b \\
\hline$I_{\max }($ inner) (kA) & 13.3 & 10.8 \\
\hline$B_{\max }$ (inner) (T) & 13.1 & 14.8 \\
\hline$I_{\max }($ outer) (kA) & 11.9 & 10.8 \\
\hline$B_{\max }$ (outer) (T) & 11.3 & 11.5 \\
\hline$I_{\mathrm{ss}}(\mathrm{kA})$ & 11.9 & 10.8 \\
\hline$B_{0-\mathrm{ss}}(\mathrm{T})$ & 10.9 & 14.7 \\
\hline$J_{\mathrm{Cu}-\mathrm{ss}}($ inner $)\left(\mathrm{kA} / \mathrm{mm}^{2}\right)$ & 1.6 & 1.1 \\
\hline$J_{\mathrm{Cu}-\mathrm{ss}}($ outer $)\left(\mathrm{kA} / \mathrm{mm}^{2}\right)$ & 1.6 & 1.5 \\
\hline
\end{tabular}

${ }^{a}$ Calculated values. Training was aborted before maximum current was reached, to assess training improvements in a subsequent thermal cycle

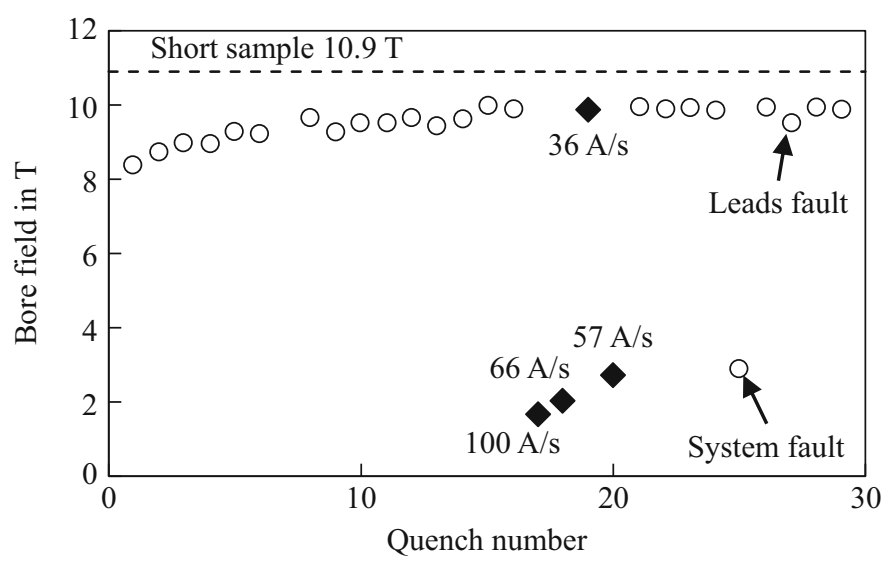

Fig. 13.15 RD-3c training history

with RD-3b in Table 13.9. RD-3c's insert coil used Rutherford cable with Oxford Superconducting Technology strand, similar to that used in RD-3b's high field insert coil (Tables 13.7 and 13.9).

\subsubsection{RD-3c Test Results}

Magnet training began after the magnet protection system was operating reliably at $2 \mathrm{kA}$. The magnet was ramped to quench with a variety of ramp rates while being cooled by a (4.4 K) two-phase LHe bath. Training quenches (Fig. 13.15) started at $77 \%$ of the un-degraded short sample limit but was pursued to only $92 \%$, where the magnet appeared to reach a plateau. These quenches exhibited large voltage spikes indicative of conductor instability. At this point ramp rate studies were initiated as shown in Fig. 13.15. It should be noted that only two of the training quench origins were in the virgin insert-module. The other quenches were equally distributed 
between the two outer modules, most starting simultaneously in the multi-turn segments of both high and low field layers, near the straight-to-curved end transition. These quenches were preceded by what was interpreted as a flux jump instability approximately $1 \mathrm{~ms}$ before resistance growth.

The RD magnets proved to be an excellent vehicle for the development of a number of important aspects of high field magnet design. But for very high field R\&D dipoles, a common-coil configuration (two bores in one coil) results in significantly greater challenges than a single-bore configuration for the same field and aperture. Not only are the usage of conductor and the magnetic forces doubled because of the second bore, but the magnet needs to be relatively longer because of the space occupied by the large radius ends. The diameter of the iron yoke also had to be increased in order to shield the opposite fields generated in the two apertures. All these necessities result in increased demand for expensive high-performance conductor and structural materials, and increases the requirements on facilities, for example the size of reaction furnaces, impregnation fixtures, and cryostats, and the cost of testing. For these reasons, the program started considering alternative solutions that would allow them to push the field limit in configurations that are relevant to accelerators and would extend the performance envelope even further.

\subsection{Sub-scale Magnet Program}

It was quickly realized that the sub-scale mechanical structure used to demonstrate the utility of the key-and-bladder concept would make an excellent R\&D vehicle for a large number of parametric studies at a much higher rate and lower cost (Hafalia et al. 2003). In previous common-coil racetrack configurations, the cable was wound around an iron pole-island, and separate side rails or rectangular bars were used to compress the straight sections of the coil layers to a prescribed load. The coil ends were supported by separate end shoes. A coil is compressed at least four times - for reaction, potting, skinning, and final assembly. To further simplify the assembly the sub-scale magnet design incorporated a stainless-steel U-shaped coil-support system (Fig. 13.16) where the return-end shoe and the side rails are integrated into one component. The thickness of the shoe was slightly larger than the cable width to prevent direct contact with the fragile conductor. The small gap was filled with epoxy during impregnation.

A traditional end shoe is used at the lead-end. A push-block is used to axially pull against the horseshoe while simultaneously pushing on the lead-end shoe in a bootstrap fashion. In the past, there were undesirable situations where the feathered ends of the end-shoes deformed the outer turn of the coil. Half of these "pinch-points" were eliminated with this new design. Machined to the same thickness as the dual layers, the horseshoe also provides a continuous sealing surface for epoxy impregnation-improving containment of the epoxy within the coil region during potting. The same horseshoe remains with the assembly from reaction through impregnation, becoming an integral part of the final coil module. A completed sub-scale magnet is shown in Fig. 13.17. 


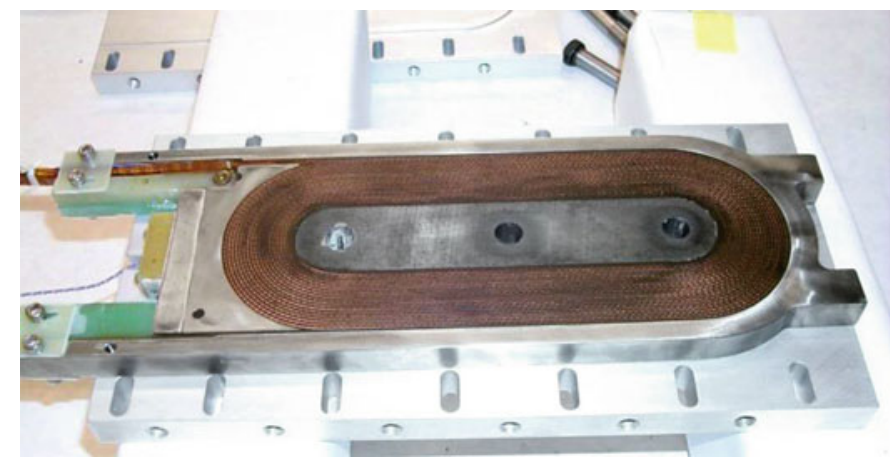

Fig. 13.16 Sub-scale coil module

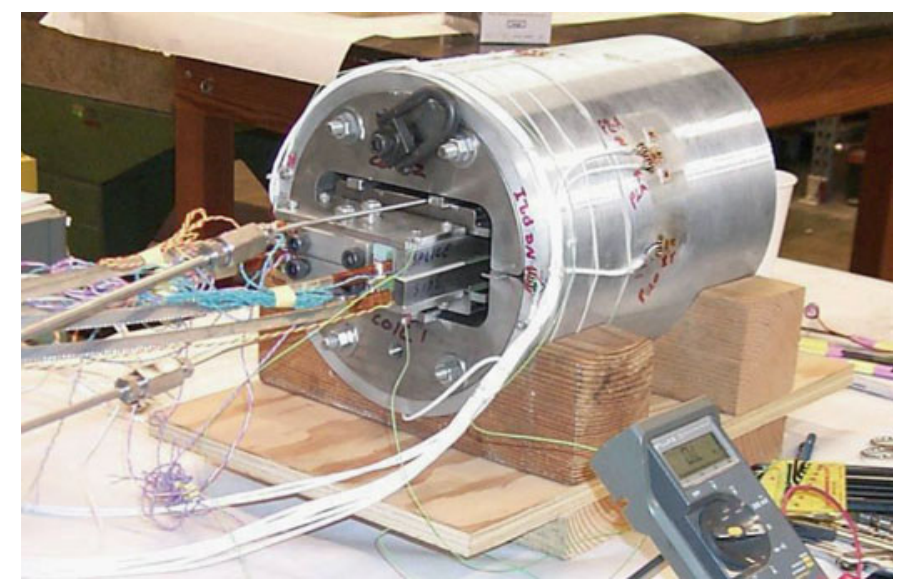

Fig. 13.17 Sub-scale test module

Since the coils were interchangeable, the philosophy was to use one "base-line" coil and one test coil. The base-line coil was a standard coil that, in most cases, had already been tested. The coils were assembled using the newly developed key-andbladder technique.

The sub-scale magnet program was governed by the following guidelines:

1. Simplicity, encompassing design and fabrication processes to facilitate iterative designs;

2. Rapid production with maximum information return;

3. Vary parameters to learn how to build low-cost, reliable coils for full-size magnets;

4. Test ideas that are too risky or expensive for full-size magnets;

5. Single-parameter tests;

6. Effectively utilize resources (both personnel and materials). 
Table 13.10 General sub-scale coil parameters

\begin{tabular}{l|l}
\hline Parameter & Value \\
\hline Number of strands & 20 \\
\hline Strand diameter $(\mathrm{mm})$ & 0.7 \\
\hline Cable width $(\mathrm{mm})$ & $7.8-8.0$ \\
\hline Cable thickness $(\mathrm{mm})$ & 1.3 \\
\hline Pitch angle $\left({ }^{\circ}\right)$ & $16-17$ \\
\hline Packing factor & 0.83 \\
\hline Insulation $(\mathrm{mm})$ & 0.15 \\
\hline
\end{tabular}

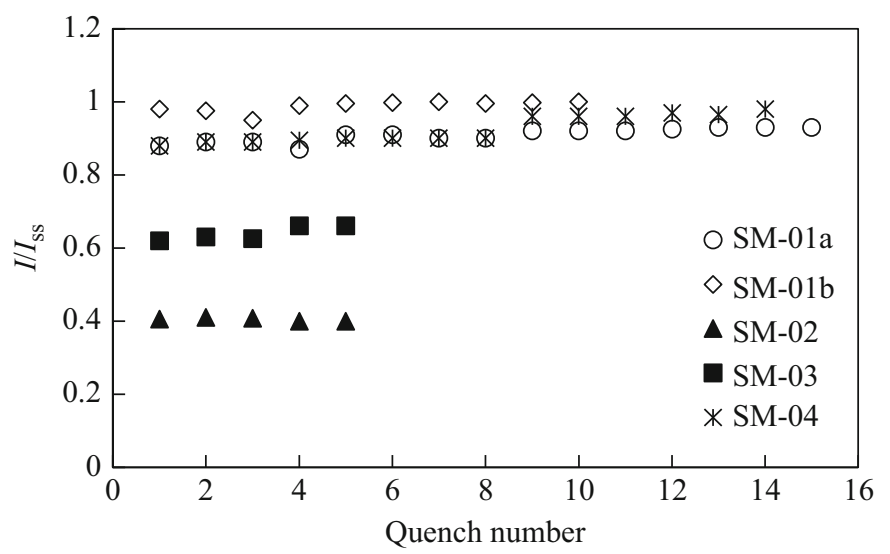

Fig. 13.18 Quench performance of SM-01, 02, 03, and 04

Over the course of the program, 14 coils were produced. The main parameters are shown in Table 13.10.

\subsubsection{SM-01}

The first pair of coils was tested in December 2001 and exhibited little training. One coil, SC-01, was highly loaded transversely in a press with a stainless-steel skin welded over it to preserve the pre-stress. A second coil, SC-02, was assembled with low pre-stress. The first test, designated SM-01a, was on a highly loaded coil pack with a shell stress of $103 \mathrm{MPa}$ at room temperature. After cool-down, the shell structure generated $248 \mathrm{MPa}$ at $4.2 \mathrm{~K}$. The magnet was warmed to room temperature and the preload was significantly reduced. After cool-down, the shell stress was $90 \mathrm{MPa}$. SM-01b started training at a higher current and quickly reached $100 \%$ of the short sample limit based on the virgin strand, see Fig. 13.18.

A summary of coil/magnet test combinations and performance is shown in Table 13.11. Strand and cable parameters are given in Table 13.12. 
Table 13.11 Sub-scale coil performance summary

\begin{tabular}{l|l|l|l}
\hline Magnet & Coils used & Current at first quench $(\mathrm{A})$ & Highest quench current (A) \\
\hline SM-01a & SC-02, SC-01 & $8925(89 \%)$ & $9391(94 \%)$ Q13 \\
\hline SM-01b & SC-02, SC-01 & $9701(97 \%)$ & $9914(99 \%)$ Q11 \\
\hline SM-02 & SC-02, SC-03 & $3801(40 \%)$ & $4005(42 \%)$ Q02 \\
\hline SM-03 & SC-02, SC-06 & $5560(63 \%)$ & $6101(69 \%)$ Q29 \\
\hline SM-04 & SC-02, SC-08 & $8776(88 \%)$ & $9789(98 \%)$ Q32 \\
\hline SM-05 & SC-01, SC-10 & $8644(98 \%)$ & $8757(101 \%)$ Q5 \\
\hline
\end{tabular}

Table 13.12 Sub-scale strand and cable parameters

\begin{tabular}{l|l|l|l|l}
\hline Coils & $\begin{array}{l}\text { Number of } \\
\text { strands }\end{array}$ & $\mathrm{Cu} /$ non-Cu & $I_{\text {ss }}(\mathrm{A})$ & $\begin{array}{l}B_{\text {peak }}\left(I_{\text {ss }}\right) \\
(\mathrm{T})\end{array}$ \\
\hline $\begin{array}{l}\text { SC-01, SC-02, } \\
\text { SC-08 }\end{array}$ & $20^{\mathrm{a}}$ & $46.5 / 53.5$ & 10,010 & 11.8 \\
\hline SC-03 & $14+7(\mathrm{Cu})^{\dagger}$ & $41 / 59+$ pure Cu strands & 9,429 & 11.4 \\
\hline SC-06 & $14+7(\mathrm{Cu})^{\mathrm{a}}$ & $\begin{array}{l}46.5 / 53.5+\text { pure } \mathrm{Cu} \text { w/ss } \\
\text { core }\end{array}$ & 8,851 & 10.5 \\
\hline SC-10 & $20^{\mathrm{a}}$ & $60 / 40$ & 9,101 & 10.6 \\
\hline
\end{tabular}

${ }^{a}$ Manufacturer: Oxford Superconducting Technology (OST), $\mathrm{Nb}_{3} \mathrm{Sn}$ technology: MJR; ${ }^{\dagger}$ Manufacturer: Intermagnetics General Corporation (IGC), $\mathrm{Nb}_{3} \mathrm{Sn}$ technology: internal tin

Fig. 13.19 Mixed-strand cable with stainlesssteel core

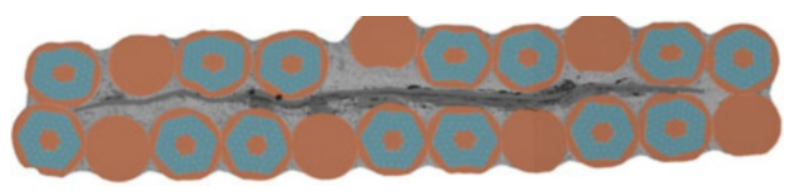

\subsubsection{SM-02 and SM-03-Mixed Strand}

Two coils made of mixed-strand cables consisting of $14 \mathrm{Nb}_{3} \mathrm{Sn}$ strands and seven strands of pure copper were manufactured and tested. One, SC-06, used mixed strand cable with a stainless-steel core, shown in Fig. 13.19.

They were tested as SM-02 and SM-03, respectively. Each of the mixed strand coils was combined with the best-performing coil from SM-01 (the low pre-stress coil SC-02). Because of the difference in elastic modulus, the mixed strand cable was mechanically unstable and proved very difficult to wind, even with a much lower winding tension ( $89 \mathrm{~N}$ compared to the usual $178 \mathrm{~N}$ ). It was discovered in the post mortem that the mixed strand cable in SM-02 was severely damaged near the lead. SM-03 performed better (Fig. 13.18), though indicating that there might still have been some damage. One should also note that, compared to the coil wound with non-mixed strand, each superconducting wire had to carry a larger current, and the critical current is likewise reduced to the ratio of $\mathrm{Nb}_{3} \mathrm{Sn}$ strands in the two cables: 
$14 / 20=70 \%$. Moreover, the large difference in thermal contraction between the $\mathrm{Nb}_{3} \mathrm{Sn}$ and copper strands may lead to damage of the conductor during cool-down.

\subsubsection{SM-04-Composite Technology Development (CTD)/ Fermi National Accelerator Laboratory (FNAL) Ceramic Insulation}

In SM-04 the standard glass cable insulation was replaced by a sleeve of ceramic fibers. The performance was comparable to the best of the standard versions (Fig. 13.18).

\subsubsection{SM-05}

Another example of the use of sub-scale coils and magnets was a test designed to investigate possible thermal shock effects on $\mathrm{Nb}_{3} \mathrm{Sn}$ performance, which became the thesis topic of a Fermi National Accelerator Laboratory (FNAL) Ph.D. student (Imbasciati et al. 2004).

Sub-scale magnet SM-05 was tested in February-March 2003. The primary purpose of this test was to evaluate the degradation of $\mathrm{Nb}_{3} \mathrm{Sn}$ cable under repetitive applied thermal stresses. During a quench in a superconducting magnet, parts of the coils can reach very high temperatures if the proper protection measures are not taken. Nevertheless, even in the case of actively protected magnets, it is necessary to determine the temperature and voltage levels that can be sustained by the magnet parts. An absolute upper temperature limit is given by the melting point of solder $(\sim 500 \mathrm{~K})$, since the quench might start near the conductor joints. For impregnated coils, a second limit could be the glass transition point of the insulation, which occurs at about $400 \mathrm{~K}$ for epoxy resins. At that temperature, the epoxy becomes soft and, even if the transition is reversible, the changes in electrical properties increase the probability of a short circuit. In the case of magnets using $\mathrm{Nb}_{3} \mathrm{Sn}$ superconductor, an additional complexity is introduced via the brittleness of $\mathrm{Nb}_{3} \mathrm{Sn}$, which could suffer permanent degradation under excessive stress.

The goal of this test was to reproduce as realistically as possible the thermomechanical conditions in a cable during a magnet quench and determine the effects of high peak temperature on magnet performance.

To simulate a high thermal stress situation in the magnet, one of the coils (SC-10) was instrumented with a spot-heater in the middle of the winding in a high field region with two voltage taps across the spot-heater section. The magnet was trained until a quench plateau was reached.

At a current below the quench current, a quench was initiated with the spotheater. The quench was left propagating along the cable instead of immediately 


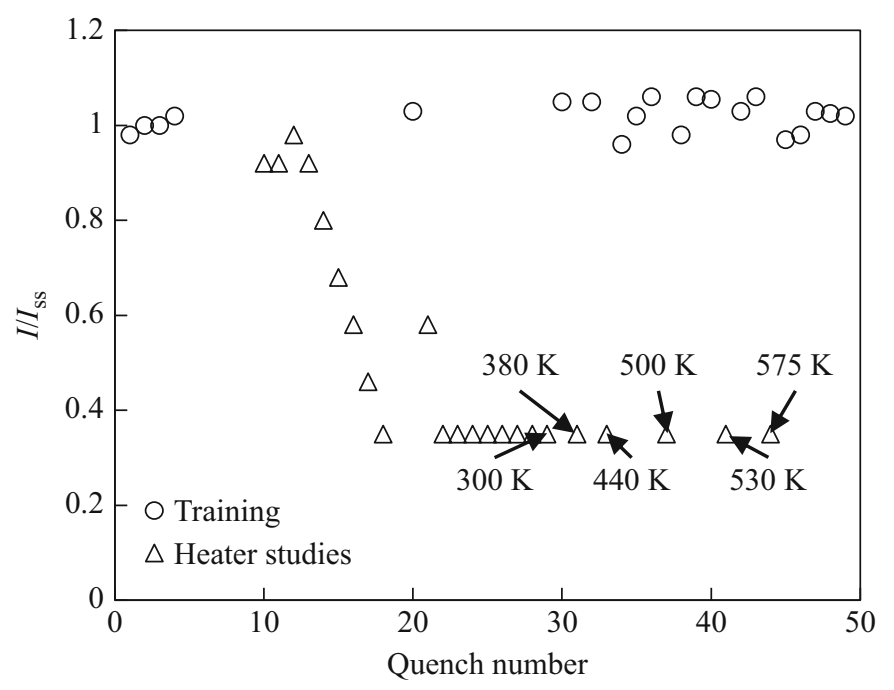

Fig. 13.20 Quench history for SM-05

switching off the current, using a pre-defined delay. The current in the normally conducting matrix allowed a well-defined amount of heating of the cable. The normal conducting zone propagates in the coil with a temperature profile that goes from the peak temperature of the starting point, to the bath temperature in other regions of the coils and in the supporting structure. The temperature gradients that are created in this fast process can induce thermo-mechanical stress. Repeated measurements of the quench current of the coils, after each excursion to high temperature, allow assessment of the critical current degradation as a function of the peak temperature during a quench.

\subsubsection{Training Summary}

The quench history is summarized in Fig. 13.20. The first quench was at $98 \%$ of the calculated short sample, which was based on virgin strand measurements. Maximum coil temperatures are indicated for the spot-heater-induced quenches. All training quenches occurred in the virgin coil, SC-10. The ramp rate dependence is shown in Fig. 13.21.

Several spot-heater-induced quenches were performed before reaching the desired temperature. The ramp rate sensitivity of SC-10 is very similar to coils previously tested. The magnet trained quickly and it was possible to induce quenches with the spot-heater after five ramps. The current at which quenches were induced varied from $8 \mathrm{kA}$ down to $3 \mathrm{kA}$. During the first thermal cycle it was not possible to reach temperatures higher than $300 \mathrm{~K}$ due to the $60 \mathrm{~V}$ limit of the power supply system. Once the limit is reached, even if the extraction system has not switched off 


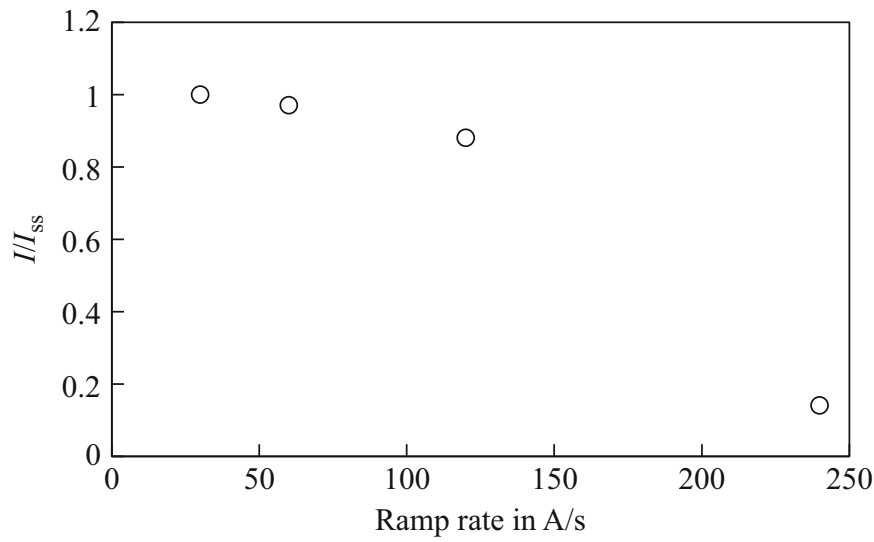

Fig. 13.21 Ramp rate dependence of SM-05

the power supply, the current starts dropping rapidly and heat propagates quickly inside the whole magnet, reducing the peak temperature values. Before starting a second cool-down, the power supply voltage was doubled to $120 \mathrm{~V}$ and the time delays were increased up to $3.5 \mathrm{~s}$. With these long time delays it was possible to introduce the extraction system at a very low current level and collect enough heat locally. After reaching temperatures higher than $350 \mathrm{~K}$ the magnet was ramped to normal quench in order to observe any degradation effects. Some degradation was observed after the temperature reached close to $400 \mathrm{~K}$. The degradation was not permanent, and after three quenches the current reached previously recorded values. Only after the last spot-heater event with a delay of $3.5 \mathrm{~s}$ and a temperature close to $600 \mathrm{~K}$ was a permanent degradation observed. The following points can be made.

1. As observed in previous magnets (RT1, SM-01b) the training is significantly reduced if the pre-stress applied to the magnet during assembly is as low as possible.

2. The thermal stresses applied to the magnet during the spot-heater studies did not reduce the performance of the magnet until a final temperature of $590 \mathrm{~K}$ was reached. After this event, the current did not recover its previous values, and a degradation of $3 \%$ was observed.

3. The thermal stresses applied with peak temperatures below $500 \mathrm{~K}$ seemed to improve the performance of the magnet.

\subsubsection{SD-01}

SD-01 was developed as a platform for training studies as a collaboration between Commissariat à l'Energie Atomique (CEA) in Saclay, France and LBNL. The two coils (SC-01 and SC-02) were powered in a dipole configuration to better mimic the Lorentz conditions of interest. The sub-scale support structure was designed to allow variable vertical, horizontal, and axial preloads, a more complex departure from the 
simple structure used for the common-coil configurations of the SM series. The first quench was at $98 \%$ of the short sample limit, and the magnet trained quickly to a stable plateau. Based on the agreement of strain measurements with values predicted by the model, the test successfully demonstrated the reliability of the new platform as a basis for further training studies. More details on the design can be found in Felice et al. (2007). A comparison of the performance of the LBNL magnets up to this period in the program can be found in Chiesa et al. (2003).

\subsection{Summary}

With an emphasis on simplicity, this six-year period of the program was essential for developing the tools and confidence needed to continue the quest for higher fields. Along with a new and versatile support structure for high field magnets and the creation of a new program for rapid technology development, the group also implemented full 3D mechanical analysis that has become an essential tool for high field magnet design.

The R\&D program, focusing on the common-coil design, was carried to a reasonable end point with RD-3c. These series of tests indicated quite clearly the difficulties incurred by going from a simple flat-coil geometry to a design that included field-quality features (auxiliary coil structures) and a reasonable bore diameter. Continued work to find ways of mitigating these challenges warrants consideration. A few more magnets of this type may have yielded a definitive answer on the viability of this design for future high field accelerator magnets, but due to finite resources and the need for the LBNL program to pursue its primary mission of pursuing accelerator magnet technology to higher fields, the group moved on to exploring block magnet designs.

The sub-scale magnet component of the program proved to be extremely productive in many ways: effective use of resources, both in terms of cost and manpower, the opportunity to perform focused experiments in a short timeframe, and the development of new diagnostics and instrumentation. This R\&D paradigm allows engineers and technicians to exercise creativity in an environment that allows them to make the mistakes that are necessary for learning.

At the end of this period, due to dwindling support, the group was forced to abandon this element of the program. Based on our experience, it is quite clear that some form of this approach should be part of every successful program.

\section{References}

Benjegerdes $\mathrm{R}$ et al (2001) Fabrication and test of $\mathrm{Nb}_{3} \mathrm{Sn}$ racetrack coils at high field. IEEE Trans Appl Supercond 11(1):2164-2167. https://doi.org/10.1109/77.920286

Caspi S, Gourlay S, Hafalia R et al (2001) The use of pressurized bladders for stress control of superconducting magnets. IEEE Trans Appl Supercond 11(1):2272-2275. https://doi.org/10. $1109 / 77.920313$ 
Chiesa L, Caspi S, Coccoli $\mathrm{M}$ et al (2003) Performance comparison of $\mathrm{Nb}_{3} \mathrm{Sn}$ magnets at LBNL. IEEE Trans Appl Supercond 13(2):1254-1257. https://doi.org/10.1109/tasc.2003.812651

Chow KP, Dietderich DR, Gourlay SA et al (1998a) Mechanical engineering and design of magnet RD-2-01. LBNL-42236; SC-MAG-630, DOE contract number AC03-76SF00098, OSTI identifier 5201571, Lawrence Berkeley National Laboratory, Berkeley

Chow K, Dietderich DR, Gourlay SA et al (1998b) Design and fabrication of racetrack coil accelerator magnets. LBNL-42507, SC-MAG-642, Lawrence Berkeley National Laboratory, Berkeley

Den Ouden A, Wessel S, Krooshoop E et al (1997) Application of $\mathrm{Nb}_{3} \mathrm{Sn}$ superconductors in highfield accelerator magnets. IEEE Trans Appl Supercond 7(2):733-738. https://doi.org/10.1109/ 77.614608

Felice H, Caspi S, Dietderich DR et al (2007) Design and test of a $\mathrm{Nb}_{3} \mathrm{Sn}$ subscale dipole magnet for training studies. IEEE Trans Appl Supercond 17(2):1144-1148. https://doi.org/10.1109/TASC. 2007.898347

Gourlay SA (1998, June) Racetrack coil model fabrication notes, SC-MAG-621

Gourlay SA, Chow K, Dietderich DR et al (1999a) Fabrication and test results of a $\mathrm{Nb}_{3} \mathrm{Sn}$ superconducting racetrack dipole magnet. SC-MAG-628, LBNL-41575. https://escholarship. org/uc/item/9qt824d9

Gourlay SA, Chow K, Dietderich DR et al (1999b) Fabrication and test results of a $\mathrm{Nb}_{3} \mathrm{Sn}$ superconducting racetrack dipole magnet. In: Luccio A, MacKay W (eds) 1999 particle accelerator conference, New York, 27 March-2 April 1999. IEEE, Piscataway, NJ, pp 171-173

Gourlay SA, Bish P, Caspi S et al (2000) Design and fabrication of a $14 \mathrm{~T}, \mathrm{Nb}_{3} \mathrm{Sn}$ superconducting racetrack dipole magnet. IEEE Trans Appl Supercond 10(1):294-297. https://doi.org/10.1109/ 77.828232

Hafalia RR, Bish PA, Caspi S et al (2002) A new support structure for high field magnets. IEEE Trans Appl Supercond 12(1):47-50. https://doi.org/10.1109/tasc.2002.1018349

Hafalia RR, Caspi S, Chiesa L et al (2003) An approach for faster high field magnet technology development. IEEE Trans Appl Supercond 13(2):1258-1261. https://doi.org/10.1109/tasc. 2003.812632

Imbasciati L, Bauer P, Ambrosio G et al (2004) Study of the effects of high temperatures during quenches on the performance of a small $\mathrm{Nb}_{3} \mathrm{Sn}$ racetrack magnet. Supercond Sci Technol 17(5): S389-S393. https://doi.org/10.1088/0953-2048/17/5/060

Jackson A et al (2001) Supercon's racetrack magnet project. Archived at https://cds.cern.ch/record/ $2638136 ? \ln =e n$

Open Access This chapter is licensed under the terms of the Creative Commons Attribution 4.0 International License (http://creativecommons.org/licenses/by/4.0/), which permits use, sharing, adaptation, distribution and reproduction in any medium or format, as long as you give appropriate credit to the original author(s) and the source, provide a link to the Creative Commons licence and indicate if changes were made.

The images or other third party material in this chapter are included in the chapter's Creative Commons licence, unless indicated otherwise in a credit line to the material. If material is not included in the chapter's Creative Commons licence and your intended use is not permitted by statutory regulation or exceeds the permitted use, you will need to obtain permission directly from the copyright holder. 